\title{
Periconceptional growth hormone treatment alters early uterine environment
}

\author{
Jill M. Koch ${ }^{1}$, Caleb O. Lemley ${ }^{2}$, Ronald R. Magness ${ }^{3}$, Matthew E. Wilson ${ }^{2}$ \\ ${ }^{1}$ Department of Medicine, Section of Cardiovascular Medicine, University of Wisconsin-Madison, Madison, USA; \\ *Corresponding Author: Matt.Wilson@mail.wvu.edu \\ ${ }^{2}$ Division of Animal and Nutritional Sciences, Davis College of Agriculture, Natural Resources and Design, West Virginia Univer- \\ sity Morgantown, Morgantown, USA \\ ${ }^{3}$ Perinatal Research Labs, Departments of Obstetrics and Gynecology and Department of Animal Science, University of Wisconsin, \\ Madison, USA
}

Received 15 January 2013; revised 27 February 2013; accepted 2 April 2013

Copyright (C) 2013 Jill M. Koch et al. This is an open access article distributed under the Creative Commons Attribution License, which permits unrestricted use, distribution, and reproduction in any medium, provided the original work is properly cited.

\section{ABSTRACT}

We have shown that an injection of sustained release growth hormone (GH), given just prior to breeding, results in lambs that are $25 \%$ heavier at birth, with an altered body composition as evidenced by an increased abdominal girth, but no difference in crown rump length. The mechanisms by which these differences occur from a single periconceptional injection are not yet known. Therefore, the objective of this experiment was to determine the effect of an injection of $\mathrm{GH}$ given prior to breeding on the composition of the uterine luminal environment and the embryo at the time of blastocyst. Ewes were synchronized with two injections of prostaglandin $F_{2} \alpha$ given eight days apart. On the day of the second injection, ewes were randomly assigned to be given an injection of sustained release $\mathrm{GH}$ or remain as controls and penned with a ram. On day 6.5 following breeding embryos were collected. Prior to surgery a jugular blood sample was taken to determine plasma progesterone and urea concentration. The uterine content of urea, prostaglandin $F_{2} \alpha$, prostaglandin $E_{2}$, transforming growth factor $\beta$-1 (TGF $\beta$ ), and nitric oxide metabolites were measured. Collected embryos were differentially stained to calculate a trophectoderm to inner cell mass ratio. The concentration of progesterone in maternal plasma was greater in the treated group compare to controls, but blood urea nitrogen was not different between groups. The uterine content of urea in the GH group was lower than that of the control group. There was a trend for TGF $\beta$ to be increased in the $\mathrm{GH}$ treated group compared to control $(P=0.07)$. There was no difference $(P>$ 0.05 ) in the total uterine content prostaglandin $F_{2} \alpha$, prostaglandin $E_{2}$ or nitric oxide metabolites. The trophectoderm to inner cell mass ratio was not different between treatment groups. Thus, we suggest that the observed difference in fetal development following periconceptional growth hormone administration just prior to breeding may be the result of an alteration in the uterine luminal environment, which may alter the cellular program of the conceptus and later development beyond the embryonic stage.

Keywords: Growth Hormone; Uterine Environment; Embryo

\section{INTRODUCTION}

Exposure to an insult or stimulus during critical periods of development can result in long lasting and possibly permanent physiological alterations, a phenomenon known as programming [1]. The impact of the uterine environment in which the conceptus and developing fetus are exposed to during gestation has been extensively studied. Particularly in sheep, studies range from the effects of early uterine environment through late gestation treatments. However, the majority of these studies focus on negatively impacting fetal growth and development and only a limited number of studies have tried to promote fetal growth and development.

It has been understood for at least 50 years that altering the early embryonic environment can greatly impact embryonic growth and survival [2]. The success of embryo transfer drops below $10 \%$ if the embryos are transferred to a uterine environment that is more than 48 
hours ahead or behind that in which the embryo was collected [3]. The stage of embryonic development also impacts the success of embryonic survival as a time dependent increase was observed in as the age of the embryo increased the rate of survival increased [2,3].

Embryo transfers into an advanced uterine environment that has been found to alter early fetal development $[4,5]$. Fetal growth was increased in ewes exposed to progesterone during the first six days of gestation [4]. Similarly, Young et al. [5] found that fetuses derived from embryos transferred to an advanced uterine environment were $42 \%$ heavier by gestational day 21 . Previously we demonstrated that a single injection of growth hormone given at or just prior to breeding increases birth weight by 10 to $25 \%$ [6]. Additionally we determined that a single injection of sustained release growth hormone given prior to breeding increased maternal IGF-I concentrations at within one week and levels were maintained for four weeks following the injections [7]

Therefore, the objective of this experiment was to determine the effect of an injection of sustained release growth hormone given just prior to breeding on the composition of the uterine environment at the time of blastocyst formation and the ratio of trophectoderm to inner cell mass is altered.

\section{MATERIALS AND METHODS}

Ewes $(n=59)$, primarily of Suffolk breeding, from the West Virginia University farm were used for the experiment. All procedures were approved by the West Virginia University Animal Care and Use Committee (ACUC No. 050805).

Estrus was synchronized by administering two injections of $20 \mathrm{mg}$ (i.m.) of prostaglandin $\mathrm{F}_{2} \alpha$ (Lutalyse, Pfizer; New York, NY) eight days apart. Ewes were randomly assigned to either a control group $(n=35)$ or a growth hormone group $(n=24)$. The growth hormone group received a single $500 \mathrm{mg}$ injection of sustained release recombinant bovine growth hormone subcutaneously (Posilac; Monstanto, St. Louis, MO) at the same time as the second prostaglandin $\mathrm{F}_{2} \alpha$ injection. This dose was previously reported to increase uterine luminal insulin like growth factor-I (IGF-I) 4-fold on day 7 of gestation and result in larger lambs at birth [6] and increased maternal IGF-I concentrations within one week of treatment [7]. Ewes were penned with a fertile ram fitted with a marking harness and ewes were checked twice daily for the appearance of new marks which occurred two to three days (day 0) following the second prostaglandin $\mathrm{F}_{2} \alpha$ injection.

\subsection{Embryo Collection}

On day 6.5 ewes underwent surgery for embryo collection. Briefly all ewes were anesthetized and main- tained on a $10 \%$ ketamine drip (Vedco; Columbus Serum, Columbus, $\mathrm{OH}$ ) and $50 \mathrm{mg} / \mathrm{ml}$ sodium pentobarbital to effect (Sigma, St. Louis, MO). A midventral incision was made in the abdominal wall to expose the uterus and the oviducts. The right and left uterine horn were flushed separately by making a small incision at the base of the uterine horn and a glass cannula with a fluted end was inserted into uterine horn. A blunted needle, attached to a glass syringe, was inserted into the oviduct through the infundibulum. Pinching off around the needle, $10 \mathrm{ml}$ of phosphate buffered saline was flushed through the oviduct and uterine horn to the glass cannula and collected in petri dish. Embryos were removed from the flushing and processed for immunosurgical lysis. Flushings were centrifuged at $2000 \times \mathrm{g}$ to pellet any cellular debris and the remaining flushing was aliquoted into microcentrifuge tubes and stored at $-20^{\circ} \mathrm{C}$ until further analysis.

\subsection{Immunosurgical Lysis}

Immnunosurgical lysis allows for the differential staining of the two main cell types of the blastocyst, the trophectoderm and the inner cell mass. Embryos were stained using a procedure previously used to stain pig embryos but modified to allow for proper staining of sheep embryos [8]. Embryos were incubated in Tyrode's Solution $(0.8 \% \mathrm{NaCl}, 0.4 \%$ polyvinyl pyrrolidone, $0.24 \%$ $\mathrm{CaCl}_{2} \cdot \mathrm{H}_{2} \mathrm{O}, 0.1 \%$ glucose, $0.02 \% \mathrm{KCl}$, and $0.01 \%$ $\mathrm{MgCl}_{2} \cdot 6 \mathrm{H}_{2} \mathrm{O} ; \mathrm{pH} 2.5$ ) for $45 \mathrm{~s}$ at $39^{\circ} \mathrm{C}$ to remove the zona pellucida. Embryos were then rinsed three times in modified phosphate buffered saline (mPBS; $1 \%$ penicillin-streptomycin, $0.4 \%$ BSA, $0.0036 \%$ sodium pyruvate and $0.0023 \%$ L-glutamine). Embryos were then incubated with $10 \mathrm{nmol} / \mathrm{L}$ trinitrobenzene sulfonic acid (Sigma, St. Louis, MO) for $30 \mathrm{~min}$ on ice. Trinitrobenzene sulfonic acid labels the surface of the trophectoderm cells with trinitrophenol groups. Embryos were then washed three times in mPBS and then placed in 0.1 $\mathrm{mg} / \mathrm{ml}$ anti-dinitrophenol (Sigma, St. Louis, MO) for 30 $\min$ at $39^{\circ} \mathrm{C}$. Anti-dintrophenol is antiserum against dintrophenol and cross reacts with trinitrophenol groups which form on the surface of the trophectoderm following exposure to trinitrobenzene. Embryos were then washed three times in mPBS and placed into a mPBS solution containing a 1:5 dilution of guinea-pig complement (Sigma, St. Louis, MO) and $0.01 \mathrm{mg} / \mathrm{ml}$ propidium iodide (Sigma, St. Louis, MO) for $30 \mathrm{~min}$ at $39^{\circ} \mathrm{C}$ in the dark. Guinea pig complement interacts with the antibodies attached to the trophectodermal cells and lyses the trophectoderm cells allowing propidium iodide into the cell. The nuclei of these cells are thus stained red. Embryos were then washed two times in MPBS before being incubated for $15 \mathrm{~min}$ in the dark at $39^{\circ} \mathrm{C}$ in $0.05 \mathrm{mmol} / \mathrm{L}$ Hoechst 33258 in mPBS (Sigma, St. Louis, MO). After $15 \mathrm{~min}$ embryos were moved into a $0.05 \mathrm{mmol} / \mathrm{L}$ Hoe- 
chst 33258 in $100 \%$ ethanol protected from light and incubated overnight at $4^{\circ} \mathrm{C}$. Hoechst can cross all membranes and stains all nuclei blue. Therefore, the nuclei of the inner cell mass appear blue, and the nuclei of the trophectoderm appear pink because they are stained with both propidium iodide and Hoechst (Figure 1). Embryos were then incubated in $100 \%$ ethanol for $30 \mathrm{~min}$ at $4^{\circ} \mathrm{C}$. Following fixation in ethanol embryos were transferred to a slide with $5 \mu \mathrm{l}$ of glycerol and covered with a glass cover slip.

The number of inner cell mass and trophectoderm cells for each embryo $(n=27$ control, $n=17 \mathrm{GH})$ were counted using an inverted microscope (Nikon TE2000) equipped with a mercury vapor lamb and a UV filter set which illuminated the embryo at $380 \mathrm{~nm}$, which is the wave length of excitation for both dyes and $420 \mathrm{~nm}$ the barrier filter. The two types of nuclei were counted by two different counters independently.

\subsection{Uterine Flushings}

\subsubsection{Maternal Progesterone}

Progesterone concentrations from jugular plasma samples were determined using RIA [9] with a sensitivity of $100 \mathrm{pg} / \mathrm{ml}$ and intra- and inter-assay CV of $4.3 \%$ and $7.7 \%$, respectively.

\subsubsection{Urea}

The concentration of urea in uterine flushing and maternal plasma were determined by a commercial assay kit

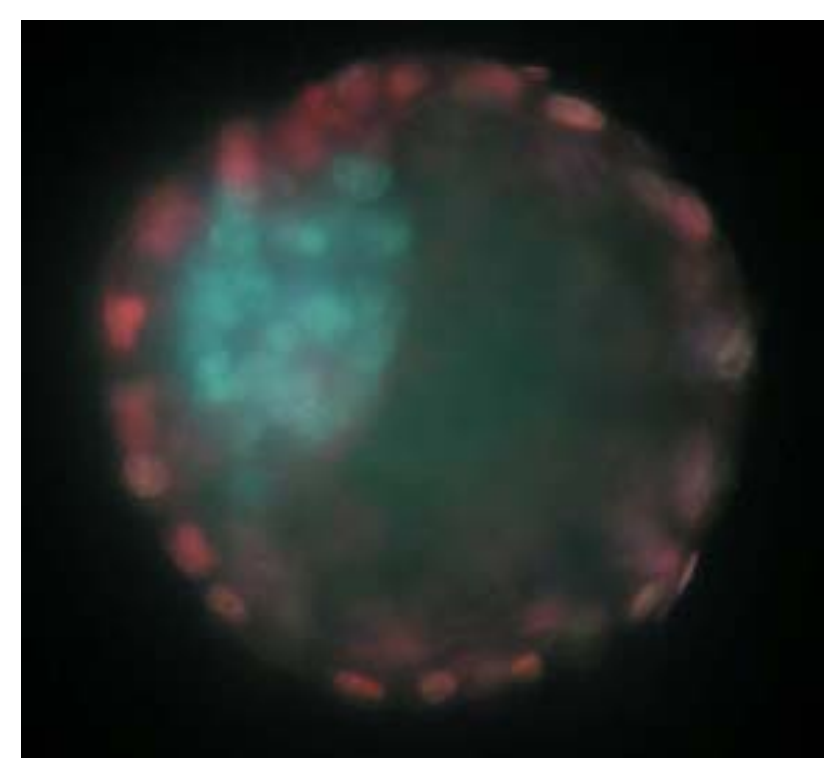

Figure 1. Differential staining of a blastocyst collected on day 6.5 by immunosurgical lysis. The inner cell mass cells are stained blue while the trophectoderm is stained pink. GH treatment did not alter the trophectoderm to inner cell mass ratio $(4.26 \pm 0.60)$ or the total number of blastomeres per embryo (40.4 \pm 3.4$)$. However, this image is of an embryo flushed form a GH treated dam. for measuring urea in biological samples (BioAssay Systems; Hayward, CA). Samples had to have duplicate values with less than a $20 \%$ coefficient of variation to be accepted for statistical analysis. Anything above 20\% is not considered acceptable for duplicates in the assays that were used for this analysis and reanalyzed.

\subsubsection{TGF $\beta$-1}

The amount of TGF $\beta-1$ in the uterine flushings was determined using a human TGF $\beta$-1 Duo Set enzyme linked immuno-sorbent assay (ELISA) kit (R\&D Systems, Minneapolis, MN) and ELAST ${ }_{\circledast}$ ELISA Amplification System (PerkinElmer Life Sciences, Boston, MA) following manufacturers' instructions and altered for uterine flushings [10]. Briefly, flat bottom 96 well Nunc-Immuno plates with MaxiSorp surface treatment (Fisher Scientific, PA), were coated with capture antibody (mouse anti-TGF $\beta-1 ; 2 \mu \mathrm{g} / \mathrm{mL}$ ) and incubated overnight at room temperature. After a wash, plates were blocked by adding blocking buffer for a minimum of 1 hour, washed, and $100 \mu \mathrm{l}$ of acid-treated uterine flushing $(1 \mathrm{~N} \mathrm{HCl}$ for TGF $\beta$ - 1 activation, $1.2 \mathrm{~N} \mathrm{NaOH/0.5} \mathrm{M} \mathrm{HEPES} \mathrm{for} \mathrm{neu-}$ tralization), or standards were added in duplicate. An eight-point standard curve consisted of 2-fold serial dilutions of recombinant human TGF $\beta-1$, starting at 125 $\mathrm{pg} / \mathrm{mL}$. Plates were incubated overnight at $4^{\circ} \mathrm{C}$, then were washed, and the detection antibody was applied (biotinylated chicken anti-human TGF $\beta-1,300 \mathrm{ng} / \mathrm{mL}$ ) for 2 hours at room temperature. Streptavidin conjugated to horseradish peroxidase was added to each well, incubated for $20 \mathrm{~min}$ at room temperature in the dark, washed, and was followed by substrate solution $\left(\mathrm{H}_{2} \mathrm{O}_{2}\right.$ mixed 1:1 with tetramethylbenzidine, R\&D Systems, Minneapolis, $\mathrm{MN}$ ) for $20 \mathrm{~min}$ at room temperature in the dark. A biotinyl-tyramide amplification step was inserted into the

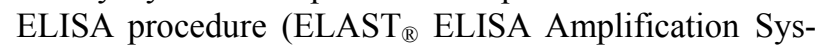
tem; PerkinElmer, Boston, MA), which increased the sensitivity to $2 \mathrm{pg} / \mathrm{mL}$. The reaction was stopped with 2 $\mathrm{N} \mathrm{H}_{2} \mathrm{SO}_{4}(50 \mu \mathrm{L} /$ well $)$ and plates were analyzed with a microplate spectrophotometer (SPECTRAmax $_{\circledast}$ PLUS $_{384}$, Molecular Devices, Sunnyvale, CA). Readings at $540 \mathrm{~nm}$ were subtracted from those at $450 \mathrm{~nm}$ for the wavelength correction, and plotted against the standard curve using the SoftMax ${ }_{\mathbb{B}}$ Pro software (version 4.6, Molecular Devices, Sunnyvale, CA). The unknown fluid validation protocol resulted in detection of $82 \%$ of recombinant TGF $\beta-1$ in the uterine flushing samples. Samples had to have duplicate values with less than a $20 \%$ coefficient of variation to be accepted for statistical analysis. Anything above $20 \%$ is not considered acceptable for duplicates in the assays that were used for this analysis and reanalyzed.

\subsubsection{Prostaglandins}

Prostaglandin $\mathrm{E}_{2}$ and prostaglandin $\mathrm{F}_{2} \alpha$ were analyzed 
by commercially available EIAS (Cayman Chemical Company; Ann Arbor, MI) and validated in our laboratory to detect prostaglandins in uterine flushing.

\subsubsection{Nitric Oxide Metabolites}

One way of assessing nitric oxide production is to measure its two metabolites nitrite $\left(\mathrm{NO}_{3}^{-}\right)$and nitrate $\left(\mathrm{NO}_{2}^{-}\right)$. Nitrite in uterine flushing was determined using a commercially available assay (Griess Reagent System; Promega; Madison, WI). The concentration of nitrite and nitrate in uterine flushing was subsequently determined using a commercial assay kit in biological samples (BioAssay Systems; Hayward, CA) in which nitrate is reduced to nitrite and total nitrite is determined.

\subsection{Statistical Analysis}

The effect of periconceptional growth hormone treatment to the dam on the concentration of protein, urea, prostaglandin $\mathrm{E}_{2}$, prostaglandin $\mathrm{F}_{2} \alpha$, TGF- $\beta 1$ in uterine flushings and maternal plasma progesterone concentration was analyzed by the analysis of variance, utilizing the general linear models procedure in SAS. The correlation between trophecoderm to inner cell mass ratio and uterine flushing components determined using the correlation procedures of SAS.

\section{RESULTS}

Periconceptional GH treatment increased maternal progesterone concentration ( $\mathrm{P}<0.05$; Figure 2). However, GH treatment did not alter maternal blood urea nitrogen $(51.03 \pm 3.11 \mathrm{mg} / \mathrm{ml})$.

Periconceptional growth hormone treatment decreased uterine urea $(\mathrm{P}<0.05)$ content on day 6.5 of pregnancy (Figure 3). There was a trend for an increase in TGF- $\beta 1$ (Figure 4; $\mathrm{P}=0.07)$. Growth hormone treatment did not alter uterine content of prostaglandin $\mathrm{F}_{2} \alpha(1677 \pm 97$ $\mathrm{ng} / \mathrm{ml})$, prostaglandin $\mathrm{E}_{2}(764 \pm 47 \mathrm{ng} / \mathrm{ml})$, nitrite and nitrate $(86.4 \pm 4.1 \mu \mathrm{M})$ and nitrite $(7.4 \pm 0.4 \mu \mathrm{M})$. Overall GH treatment did not alter the trophectoderm to inner cell mass ratio $(4.26 \pm 0.60)$ or the total number of blastomeres per embryo $(40.4 \pm 3.4)$.

\section{DISCUSSION}

We were able to identify a number of treatment differences both in the maternal hormonal and uterine environmental milieu that could explain how periconceptional treatment with growth hormone might program both the prenatal and postnatal growth and physiology of the offspring of treated dams.

The concentration of progesterone in the periconceptional GH treatment group was higher than the concentration observed in the control group. Progesterone administration is one mechanism used to study the impact

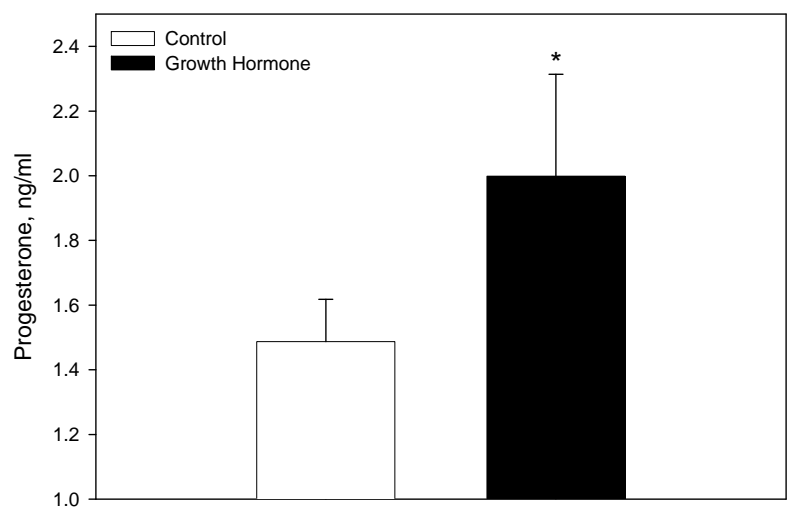

Figure 2. Maternal progesterone concentration on day 6.5 of gestation in control ewes and those treated a periconceptional $\mathrm{GH}$ injection. Values are means $+\mathrm{SEM} .{ }^{*}$ Indicates a treatment difference $\mathrm{P}<0.05$.

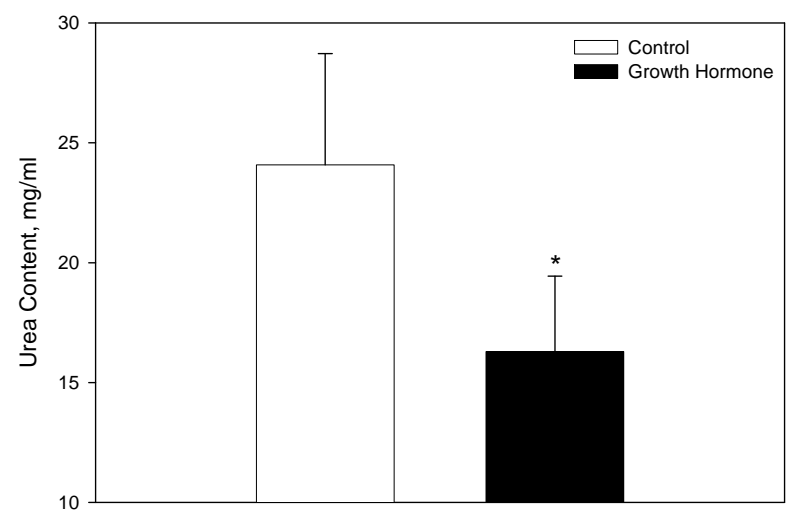

Figure 3. Uterine urea content on day 6.5 of gestation in control ewes and those treated a periconceptional GH injection. Values are means + SEM. ${ }^{*}$ Indicates a treatment difference $\mathrm{P}<$ 0.05 .

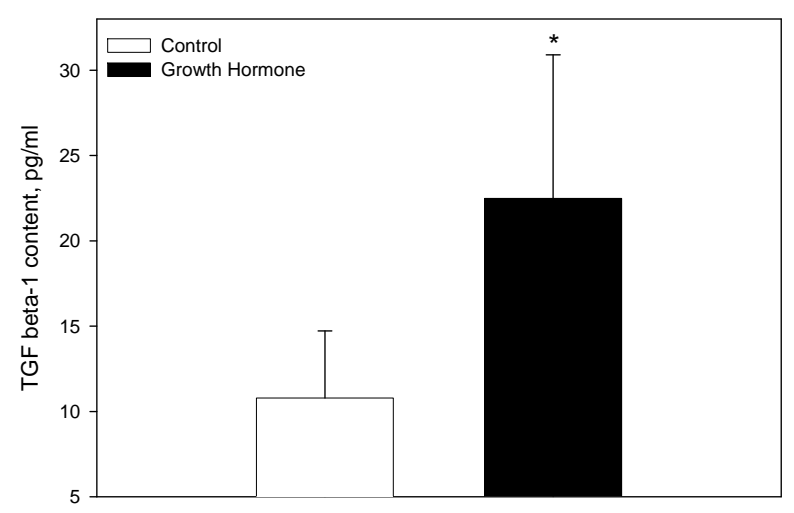

Figure 4. Uterine TGF $\beta$ - 1 content on day 6.5 of gestation in control ewes and those treated a periconceptional GH injection. Values are means \pm SEM. ${ }^{*}$ Indicates a treatment difference $\mathrm{P}=$ 0.07 .

of the uterine environment on embryonic development [4].

Progesterone treatment during early pregnancy has 
been shown to increase both fetal mass and crown rump length later in gestation. Fetal growth was increased in ewes exposed to progesterone from days $1-3,3-6$ or 1 - 6 of gestation. Progesterone treatment starting on day one had the greatest impact on fetal growth in that both fetal mass and crown rump length increased [4]. Progesterone exposure on only days 3 - 6 increased fetal mass, but not to the extent of that observed with day one treatment and fetal crown rump length was not different [4]. In this experiment embryos transferred into a uterine environment on day 3, which was previously primed by progesterone administration starting on days $1-3$, had approximately $7 \%$ greater fetal mass on day 76 compared to control fetuses [4]. Embryos transferred to a more advanced uterine environment on day 3 (i.e., a day 6 uterine environment) for three days before being transferred back into their original uterine environment (i.e., now a day 6) were found to be $42 \%$ heavier at day 21 of gestation [5]. Maxfield et al. [11] utilized the same transfer methods in which day three embryos were transferred to a uterine environment advanced by three days (i.e., day 6 environment), for three days, and then transferred back to a day six environment. The fetuses collected from this experiment had altered muscle development. While there was no difference in fetal weight or crown rump length, those embryos transferred to an asynchronous environment had a greater number of muscle fibers compared those maintained in a synchronous environment [11]. This indicates that only a small change in the embryonic environment, for a short amount of time, can result in "fetal programming."

In the current experiment no difference was observed in the total number of blastomeres or the trophectoderm to inner cell mass ratio even those lambs that are born to ewes treated with a periconceptional injection of GH are approximately $10 \%$ larger at birth [6]. Progesterone treatment from days 1 - 3 advanced embryonic development as measured by the number of blastomeres per embryo on day 3 [4]. In a similar study in which progesterone was administered from day 4-9 of gestation, no difference was found in conceptus development on day 10 [12]. These two studies provide further insight as to why no difference in blastocyst cell number, or trophectoderm to inner cell mass ratio was detected and can include the time of embryo collection and the time treatment was applied.

Histotrophic nutrients bathe the embryo in the uterus and consist of enzymes, growth factors, ions, cytokines, hormones, adhesion molecules and transport proteins [13-15]. In this study TGF $\beta-1$ was elevated in uterine flushings of those ewes treated with a periconceptional injection of GH. Previously our laboratory reported that periconceptional injection of GH increased IGF-I in a dose dependent manner on day 7 [6]. Growth factors play an important role in embryonic and fetal growth and appear to be differentially expressed in uterine environment from the single cell stage through gestation [16]. In particular IGF-I is known to be the most important fetal growth promoter and correlated with birth weight and crown rump length [17]. Further investigation into other growth factors that are secreted by the oviductal and uterine endothelium that are differentially expressed in response to a periconceptional $\mathrm{GH}$ injection may provide additional insight into what growth factors program embryonic cells leading to more efficient placenta and larger lambs at birth.

In the current experiment, the concentration of urea was elevated in uterine flushing in those animals treated with a periconceptional injection of GH. This finding may be a result of changes in amino acid metabolism. Growth hormone should stimulate the accretion of lean muscle mass leading to a reduction in amino acid oxidation and overall less circulating urea and decreasing urea in uterine flushings. While urea may not directly program the embryo, it may be correlated with a reduction in the overall amino acids in circulation and in uterine flushings. Unfortunately the methods used in this experiment to collect embryos diluted uterine flushings by 10 - 20 folds and made it impossible to detect amino acids.

In conclusion, periconceptional $\mathrm{GH}$ administration appears to alter some aspects of the uterine environment which may be mediated through an increase in maternal progesterone, but further investigation into classification in changes in uterine environment following periconceptional GH treatment is required. The changes that were observed did not appear to alter embryonic growth as determined by total cell number or trophectoderm to inner cell mass ratio. Future studies will examine programming of the embryo as a result of changes in uterine environment may link periconceptional growth hormone treatment to increase placental efficiency and larger lambs at birth.

\section{ACKNOWLEDGEMENTS}

This work is published with the approval of the Director of West Virginia Agriculture and Forestry Experiment Station as scientific paper \#3170. This project was supported by Hatch project 468 and a West Virginia University Faculty Senate Research Grant (MEW); and HL49210, HL087144 and HD38843 (RRM).

\section{REFERENCES}

[1] Godfery, K.M. and Barker, D.J. (2000) Fetal nutrition and adult disease. American Journal of Clinical Nutrition, 71, 1344S-1352S.

[2] Moore, N.W. and Shelton, J.N. (1964) Egg transfer in sheep: Effect of degree of synchronization between donor and recipient, age of egg, and site of transfer on the sur- 
vival of transferred eggs. Journal of Reproduction and Fertility, 7, 145-152. doi:10.1530/jrf.0.0070145

[3] Rowson, L.E.A. and Moor, R.M. (1966) Embryo transfer in the sheep: The significance of synchronizing oestrus in the donor and recipient animal. Journal of Reproduction and Fertility, 11, 207-212. doi:10.1530/jrf.0.0110207

[4] Kleemann, D.O., Walker, S.K. and Seamark, R.F. (2004) Enhanced fetal growth in sheep administered progesterone during the first three days of pregnancy. Journal of Reproduction and Fertility, 102, 411-417. doi:10.1530/jrf.0.1020411

[5] Young, L.E., Butterwith, S.C. and Wilmut, I. (1996) Increased ovine fetal weight following transient asynchronous embryo transfer is not associated with increased placental weight at day 21 of gestation. Theriogenology, 45, 231. doi:10.1016/0093-691X(96)84704-2

[6] Costine, B.A., Inskeep, E.K. and Wilson, M.E. (2005) Growth hormone at breeding modifies concetpus development and postnatal growth in sheep. Journal of Animal Science, 83, 810-815.

[7] Koch, J.M., Wilmoth, T.A. and Wilson, M.E. (2010) Periconceptional growth hormone treatment alters fetal growth and development in lambs. Journal of Animal Science, 88, 1619-1625. doi:10.2527/jas.2009-2392

[8] Rivera, R.M., Youngs, C.R. and Ford, S.P. (1996) A comparison of the number of inner cell mass and trophectoderm cells of preimplantation Meishan and Yorkshire pig embryos at similar developmental states. Journal of Reproduction and Fertility, 106, 111-116. doi:10.1530/jrf.0.1060111

[9] Sheffel, C.E., Pratt, B.R. Ferrell, W.L. and Inskeep, E.K. (1982) Induced corpora lutea in the postpartum beef cow. II. Effects of treatment with progestogen and gonadotropins. Journal of Animal Science, 54, 830-836.

[10] Holaskova, I. (2007) Distribution of transforming growth factor $\beta-1$, TGF receptor II and decorin in the sheep uterus shortly after breeding II. Effect of TGF $\beta$ - 1 on gene expression in the sheep uterus at the time of embryo attachment III. Concentration of TGF $\beta-1,2$, and 3 in beef bull and ram seminal plasma, Dissertation, West Virginia University, Morgantown.

[11] Maxfield, E.K., Sinclair, K.D., Dunne, L.D., Broadbent, P.J., Robison, J.J., Steward, E., Kyle, D.G. and Maltin, C.A. (1998) Temporary exposure of ovine embryos to an advanced uterine environment does not affect fetal weight but alters fetal muscle development. Biology of Reproduction, 59, 321-325. doi:10.1095/biolreprod59.2.321

[12] Ashworth, C.J. and Bazer, F.W. (1989) Changes in ovine conceptus and endometrial function following asynchronous embryo transfer or administration of progesterone. Biology of Reproduction, 40, 425-433. doi:10.1095/biolreprod40.2.425

[13] Spencer, T.E. and Bazer, F.W. (2004) Uterine and placental factors regulating conceptus growth in domestic animals. Journal of Animal Science, 82, E4-E13.

[14] Aguilar, J. and Reyley. M (2005) The uterine tubal fluid: secretion, composition and biological effects. Animal Reproduction, 2, 91-105.

[15] Kleemann, D.O., Walker, S.K. and Seamark, R.F. (1994) Enhanced fetal growth in sheep administered progesterone during the first three days of pregnancy. Journal of Reproduction and Fertility, 102, 411-417.

[16] Watson, A.J., Watson, P.H., Arcellanal-Panlilio, M., Warnes, D., Walker, S.K., Schultz, G.A., Armstrong, D.T. and Seamark, R.F. (1994) A growth phenotype map for ovine preimplantation and development. Biology of Reproduction, 50, 725-733. doi:10.1095/biolreprod50.4.725

[17] Bauer, M.K., Harding, J.E., Bassett, N.S., Breier, B.H., Oliver, M.H., Gallaher, B.H., Evans, P.C., Woodall, S.M. and Gluckman, P.D. (1998) Fetal growth and placental function. Molecular and Cellular Endocrinology, 140, 115-120. doi:10.1016/S0303-7207(98)00039-2 